San Jose State University

SJSU ScholarWorks

Faculty Publications

Psychology

January 2013

\title{
Impact of older adults' experience with psychotherapy on treatment engagement
}

\author{
Erin L. Woodhead \\ San Jose State University, erin.woodhead@sjsu.edu \\ I. I. Ivan \\ Palo Alto University \\ E. E. Emery \\ Rush University Medical Center
}

Follow this and additional works at: https://scholarworks.sjsu.edu/psych_pub

Part of the Psychology Commons

\section{Recommended Citation}

Erin L. Woodhead, I. I. Ivan, and E. E. Emery. "Impact of older adults' experience with psychotherapy on treatment engagement" Clinical Gerontologist (2013): 260-273. https://doi.org/10.1080/

07317115.2013 .767869

This Article is brought to you for free and open access by the Psychology at SJSU ScholarWorks. It has been accepted for inclusion in Faculty Publications by an authorized administrator of SJSU ScholarWorks. For more information, please contact scholarworks@sjsu.edu. 


\title{
Running Head: EXPERIENCE WITH PSYCHOTHERAPY
}

\author{
Impact of Older Adults' Experience with Psychotherapy \\ on Treatment Engagement \\ Erin L. Woodhead, Ph.D. ${ }^{1}$ \\ Iulia I. Ivan, B.A. ${ }^{2}$ \\ Erin E. Emery, Ph.D. ${ }^{3}$ \\ ${ }^{1}$ San José State University, San Jose, CA \\ ${ }^{2}$ Palo Alto University, Palo Alto, CA \\ ${ }^{3}$ Department of Behavioral Sciences, Rush University Medical Center, Chicago, IL
}

Address correspondence to:

Erin L. Woodhead, Ph.D.

Department of Psychology

San José State University

Erin.Woodhead@sjsu.edu

408-924-5600 


\begin{abstract}
The goal of the study was to characterize older adults' experience with psychotherapy and examine its impact on engagement in psychotherapy. The study included fifty adults over age 60 who screened positive for depression and participated in the BRIGHTEN Program, an interdisciplinary geriatric mental health program. Qualitative analyses revealed five themes leading to treatment initiation: health concerns, family issues, the experience of depressive symptoms, and beliefs about what participants could get from psychotherapy. Those without a history of mental health treatment were more likely to endorse health concerns as a treatment motivator, and were more likely to terminate treatment early. Future research is warranted to determine how to effectively engage older adults seeking mental health treatment for the first time.
\end{abstract}

Keywords: Depression, Therapies, Aging 
Impact of Older Adults' Experiences with Psychotherapy on Treatment Engagement

Understanding the factors involved in the decision to seek mental health treatment among older adults is important for clinicians and researchers, particularly given the low rates of psychotherapy utilization among older adults (e.g., Crabb \& Hunsley, 2006; Klap, Unroe, \& Unützer, 2003; Crystal, Sambamoorthi, Walkup, \& Akincigil, 2003) and the significant rates of need for treatment (e.g., Jeste et al., 1999; Qualls, 1998).There are multiple contextual factors relevant to all adult age groups that influence the decision to seek treatment for depression. One framework proposes that the type and amount of treatment results from an interaction of life stressors, social resources, severity and chronicity of depressive symptoms, and sociodemographic factors (e.g., Cronkite \& Moos, 1995). Life stressors may play a particularly large role in the treatment seeking behavior of older adults who experience late onset depression (e.g., Fiske, Wetherell, \& Gatz, 2009). In Fiske and colleagues' model of late life depression, stressful life events and loss of social roles are linked to activity curtailment and subsequent depression. Possibly, stressful life events may be more likely to trigger mental health treatment seeking among older adults without a history of depression, as opposed to those who have successfully sought treatment in the past.

There is also reason to believe that older adults incorporate personal and vicarious information into their conceptualizations of depression and mental health treatment. For example, Wittink and colleagues found that older adults' knowledge and beliefs about depression were gleaned from life events, social relationships, and the clinical encounters they had with health care professionals about the diagnosis of 
depression (Wittink, Dahlberg, Biruk, \& Barg, 2008). This suggests that older adults complement medical knowledge of depression with their own conceptualization of depression, gained from experience from their own lives and the experiences and knowledge of friends and family members. This type of experiential knowledge may impact treatment engagement. In support of this, research in the area of health-related decision making among older adults suggests that experience with an illness or treatment may play a larger role in the decision making process of older adults as compared to other age groups (e.g., Berg, Meegan, \& Klaczynski, 1999; Pierce, 1993; Woodhead, Lynch, \& Edelstein, 2011).

Given the direct impact of depression on functionality, as well as on many other health conditions (e.g., Beekman et al., 2002; Meeks, Murrell, \& Mehl, 2000), studying precipitants of depression treatment seeking among older adults is critical. To that end, the current exploratory study used qualitative interviews to characterize older adults' experience with psychotherapy and examine the impact of experience on engagement in psychotherapy. We also sought to determine systematic differences in reasons for seeking treatment among those with and without a prior history of mental health treatment for depression. The goals of the study were to: 1) identify systematic differences in reasons for seeking psychotherapy among older adults with prior mental health treatment experience, compared to those without prior experience, and 2) determine whether experience with psychotherapy was associated with psychotherapy engagement.

For the first research question, we hypothesized that life stressors would play a larger role in the treatment motivations for older adults who have never sought mental 
health treatment before, based on the model of late life depression proposed by Fiske and colleagues (2009). For the second research question, we hypothesized that those with prior treatment experience would have increased adherence to psychotherapy; we based this hypothesis on research suggesting that reliance on experiential information in older adulthood is consistent with motivational shifts in the goals of decision making (e.g., Finucane, 2008; Mikels et al., 2010; Peters, Hess, Västfjäll, \& Auman, 2007), together with research indicating that psychotherapy is effective for most adults.

Method

\section{Participants}

Participants in the current study were 50 adults over age 60 who screened positive for depression and agreed to enrollment in the BRIGHTEN Program (Bridging the Resources of a Geriatric Health Team via Electronic Networking; see below for screening procedure). Participants were referred to the BRIGHTEN program either through primary and specialty care clinics at an academic medical center or through the general medicine clinic of a county hospital. Participants ranged in age from 60 to 93 (M $=71.9, \mathrm{SD}=8.9)$. Additional demographic information about the participants is presented in Table 1. Participants did not receive compensation for participating in the study, though psychotherapy services were provided free of charge as part of a larger grant examining the outcomes of the BRIGHTEN program. The current study was approved by the Institutional Review Boards at Rush University Medical Center and John H. Stroger Hospital System. 


\section{Materials}

Demographic Questionnaire. As part of the initial assessment for the BRIGHTEN program, participants were asked a series of background questions, including age, selfreported health, education, race, gender, and whether the participant had a personal history of mental health treatment.

Decision Making Questionnaire. For the purposes of the current study, a decision making questionnaire was designed by the first author to assess the participant's personal and vicarious experience with mental health treatment (Woodhead, Ivan, \& Emery, 2012). The questionnaire is based on dual processing theory (Epstein, 1990, 1991; Epstein, Pacini, Denes-Raj, \& Heier, 1996), which conceptualizes decision making as relying on experiential and analytic reasoning. The current study focuses on the experiential component of decision making, as researchers suggest that older adults may rely on the experiential system more than other age groups (e.g., Finucane, 2008; Mikels et al., 2010; Peters, Finucane, MacGregor, \& Slovic, 2000).

The current study is based on two questions in the decision making questionnaire that were designed to elicit discussion from the participants about specific beliefs and experiences pertinent to depression treatment, and how important this information was to the decision to pursue psychotherapy for depression. The questions were: 1) Please briefly describe the personal experience you have had with mental health treatment [personal experience], and 2) Please briefly describe the experience your friends and family have had with mental health treatment [vicarious experience]. Participants were told that mental health treatment could include counseling, therapy, or medication for issues such as stress management, anxiety, and depression. After each 
question, a trained research assistant followed up on participant responses with specific questions about each participant's experience, and how those experiences influenced beliefs about mental health treatment.

Geriatric Depression Scale (GDS) - Short Form. The 15-item GDS (Yesavage et al., 1983) assesses depressive symptoms among older adults using a yes/no response format. Scores between 5 and 10 are considered "possible depression" and scores greater than 10 are considered "probable depression." All participants completed the GDS in their initial intake session with the BRIGHTEN program coordinator (a geriatric clinical social worker) as part of a comprehensive clinical interview.

Psychotherapy Engagement. Four psychotherapy engagement index variables were created to examine whether history of mental health treatment was associated with: 1) whether or not the participant started treatment (yes/no), 2) whether the participant dropped out of treatment prior to psychotherapy termination (yes/no), 3) number of appointments attended, and 4) psychotherapy attendance rate, calculated as number of sessions attended divided by number of sessions scheduled.

Procedure

Participants were initially screened for depressive symptoms in their primary care clinic via a three item screening measure, comprised of the Patient Health Questionnaire - 2 item (PHQ-2; Spitzer, Kroenke \& Williams, 1999) plus one anxiety item developed by program staff. Response format was modified from the original PHQ-2 to yes/no format for ease of older adult administration. The questions were whether, in the past two weeks, the participant was bothered by 1 ) little interest or pleasure in doing things he/she usually enjoys, 2) feeling down, sad or hopeless or 3) 
feeling worried or nervous. Screening positive was defined as a 'yes' response to one of these three questions. When participants screened positive, they were referred to the BRIGHTEN program and were scheduled for a comprehensive psychosocial assessment with the social work program coordinator, which included measures of symptom severity. Following the assessment, a de-identified report was sent via email to the BRIGHTEN interdisciplinary "virtual" team, which consisted of providers from psychology, social work, psychiatry, chaplaincy, nutrition, occupational therapy, and physical therapy. All disciplines responded with treatment plan suggestions.

Recommendations for psychotherapy were based on symptom severity and the issues discussed during the initial assessment. Psychotherapy was recommended for some participants with low GDS scores if the program coordinator felt that the participant was minimizing symptoms on the GDS while reporting significant distress in the clinical interview.

If psychotherapy was recommend, treatment modalities included interpersonal psychotherapy (IPT) or cognitive-behavioral psychotherapy (CBT). Treatment modality was suggested by the interdisciplinary team based on the participant's presenting problems, and determined via collaboration between the clinician and supervisor. Those with predominantly interpersonal stressors received IPT, while those whose cognitive frame around their stressors was problematic, or had predominant behavioral activation problems, received CBT.

Following input from the interdisciplinary team, the treatment recommendations were communicated to the patient and a collaborative plan was developed to pursue some or all of the treatment recommendations. If a participant expressed interest in 
psychotherapy, they were contacted by a therapist to start treatment. During the course of treatment, the social work program coordinator contacted participants regularly to check on their progress, provide case management as needed, and recommend additional resources. Appointment reminder calls were initiated by the therapist on an individual basis. A research assistant contacted participants after the treatment plan was reviewed and before they initiated psychotherapy to administer the study measures. Responses to the interview were transcribed and coded for analysis. Analysis Plan

To analyze the qualitative data, the first and second authors initially read the responses to the two decision making questions in order to identify overarching themes in treatment seeking. This resulted in identification of five major categories of reasons for seeking treatment. To provide a validity check on the categories, an independent rater was provided with a sample of 15 transcripts and asked to produce themes related to motivation for attending treatment. The independent rater produced five themes that were consistent with themes produced by the first and second authors (expectations, desires, and/or beliefs that therapy will help, wanting relief from symptoms of depression, interpersonal/family problems, medical problems, and previous experience with therapy through personal experience or that of friends/family members).

When the categories were finalized, the first and second author worked together to refine the codes and apply them to all statements in the transcripts. To ensure that the codes were adequately defined and could be reliably applied to statements within the transcripts, two raters not associated with the project were asked to code a sample of 20 transcript statements into the five overarching categories. An intraclass correlation 
coefficient (ICC) was used to determine interrater reliability for the two independent raters. Independent samples t-tests and chi-square tests were used to examine whether endorsement of the motivational categories differed by gender, race, self-reported health, and severity of depressive symptoms.

For the first research question, examining whether motivations for seeking treatment differed by history of experience with mental health treatment, we used $2 \times 2$ chi-square tests to compare endorsement of each category by those with and without a history of treatment.

For the second research question, examining whether prior experience with mental health treatment was associated with psychotherapy engagement, chi-square tests were used to examine associations for the two dichotomous engagement variables (starting and early termination); independent samples t-tests were used to examine associations for number of sessions attended and attendance rate.

Results

Of the 50 participants, $33(66 \%)$ reported a personal history of mental health treatment. Approximately half of these participants (56.3\%) reported a positive experience in prior treatment. The number of prior treatment experiences ranged from one to four $(M=1.56, S D=0.98)$. Approximately 67 percent $(n=24)$ of prior experiences were individual counseling with a psychologist or social worker, 8 percent $(n=3)$ were group or couples counseling, and 25 percent $(n=9)$ were medication management with a psychiatrist. Participants who had prior mental health treatment were more likely to be younger (average age of 69.7 versus 75.8 ), $t(48)=2.39, p=$ 0.02 , and more educated, $t(48)=-2.51, p=0.02$. Of note, those with and without prior 
treatment experience did not have significantly different scores on the GDS (M = 7.4 vs. 6.4 , respectively).

Psychotherapy engagement did not vary significantly by race (white vs. nonwhite), treatment modality (IPT vs. CBT), or depression severity (positive vs. negative GDS score; Table 2).

Qualitative Results: Treatment Seeking Differences by Experience

Reliability of the independent raters was acceptable for coding participant statements into the overarching themes $(\mathrm{ICC}=0.869,95 \% \mathrm{Cl}=0.666-0.948$; total of 4 disagreements). The first category, family issues motivating treatment, was endorsed by $32 \%$ of respondents and was defined as participants talking specifically about a family concern, either new or long-standing, that led them to seek professional help. The second category, health motivations, was endorsed by $16 \%$ of participants and referred to discrete health events that prompted treatment, primarily due to concern about upcoming procedures or difficulty coping with a health condition. Approximately $40 \%$ of participants were motivated to attend treatment due to positive outcomes seen in others who sought mental health treatment. Participants described these experiences in response to the open-ended question regarding friends or family members who had received mental health treatment. The fourth category, beliefs about treatment outcomes, was endorsed by $22 \%$ of participants. This category captured statements about what participants were hoping to get out of psychotherapy, such as learning new coping skills. The fifth category, experience of depressive symptoms, was the most commonly cited reason for seeking treatment, endorsed by $54.0 \%$ of participants. This 
category was applied when the participant explicitly discussed the symptoms of depression and their inability to cope with the symptoms on their own (Table 3).

There were no significant differences in motivational categories by gender, selfreported health, race, or severity of depressive symptoms except that those endorsing health problems as a treatment motivator reported significantly worse health, $t(48)=-$ $2.15, p=0.04$.

Treatment Motivations by Psychotherapy Experience

We hypothesized that those without a history of mental health treatment would be more likely to seek treatment based on specific stressors. This hypothesis was supported; the category of health motivations was significantly more likely to be endorsed by individuals who had not previously sought mental health treatment (35.3\% vs. $6.1 \%), X 2(1, N=50)=7.13, p=0.008$. The other categories of motivators were equally reported by those with and without a history of mental health treatment. Association between Treatment Experience and Psychotherapy Engagement

There were no significant differences in starting psychotherapy by history of treatment, $\mathrm{X}^{2}(1, \mathrm{~N}=50)=0.09, p=0.75$. There were significant differences in rate of early termination by history of treatment, $X 2(1, N=50)=12.15, p<0.001$; participants without a history of treatment were more likely to terminate early as compared to those with a history of treatment $(41.2 \%$ vs. $3.0 \%)$. Of note, only one person who had a history of treatment terminated early. Participants without a history of treatment also had a significantly lower attendance rate than those with a history of treatment $(60.0 \%$ vs. $86.1 \%$ attendance rate), $t(37)=-2.72, p=0.01$, and attended approximately half as 
many sessions as those with a history of treatment $(M=5.6, S D=5.9$ vs. $M=10.9, S D$ $=8.6$, respectively), $t(38)=-2.03, p=0.05$.

\section{Discussion}

The results of the current study suggest that older adults seek mental health treatment for multiple reasons, including health concerns, family issues, the experience of depressive symptoms, and beliefs about what they can get from psychotherapy, either based on personal or vicarious experience. We found that health concerns were reported as treatment motivators significantly more often among participants who did not have a history of mental health treatment. Although older adults presenting for mental health treatment for the first time had similar depression severity scores compared to those with a history of treatment, they were significantly more likely to terminate treatment early and attended approximately half as many sessions as those with a history of treatment.

These findings are important for several reasons. First, we found that treatment initiation rates were similar regardless of whether the participant had prior experience with mental health treatment. This supports existing research on the effectiveness of engagement via primary care-based interdisciplinary mental health programs, which may reduce stigma for older adults seeking treatment for the first time (c.f., Areán et al., 2005). Although prior experience with mental health treatment did not impact treatment initiation, it did impact treatment maintenance. Specifically, those with a history of treatment were more likely to complete treatment and attend more sessions than those without a history of treatment. Of note, this finding was true regardless of whether the participant reported that the prior treatment experience was positive or negative. 
This finding suggests that additional effort may be needed to help older adults stay engaged in treatment if they are seeking it for the first time. This could include modifying the structure of psychotherapy to best fit the participant's needs, such as through regular reminder calls and the option of doing telephone sessions and/or inhome sessions (Yang \& Jackson, 1998). Although not studied among older adults, other strategies to reduce early termination include pre-therapy preparation, treatment negotiation, and case management (Ogrodniczuk, Joyce, \& Piper, 2005).

Congruent with Fiske and colleagues' (2009) model of late life depression, we found that health concerns were more likely to motivate treatment initiation among those who had never sought treatment. As suggested by Fiske et al., late life depression may develop due to curtailment of activities, potentially in response to changes in health or other stressors that are more prevalent in late life. Older adults seeking treatment for the first time due to a new health condition may benefit from education about the role of psychotherapy in managing health conditions, and/or incorporation of additional treatment modalities to manage chronic conditions (e.g., mindfulness-based stress reduction; Bohlmeijer, Prenger, Taal, \& Cuijpers, 2010).

Taken together, the results of the current study suggest that older adults without a history of mental health treatment may be at risk for early termination. These individuals may need additional outreach and orientation at the start of psychotherapy (c.f., Sirey, Bruce, \& Alexopoulos, 2005; Sirey, Bruce, \& Kales, 2010). For example, clinicians could spend additional time reviewing what the patient can expect from psychotherapy and addressing barriers to treatment that are specific to that individual. Flexibility may also be required in the structure of psychotherapy, such as incorporating 
frequent reminder calls and telephone or in-home sessions. Further research is needed to determine why older adults without a history of mental health treatment are at risk for early termination. Potential factors include lack of progress in psychotherapy and/or stigma around seeking treatment.

\section{Limitations}

These findings should be considered in light of some limitations. The semistructured interview was developed for use in the study. Additional studies using this measure are needed to establish the reliability and validity of this format for assessing factors in the decision to pursue psychotherapy. The coding categories used to guide analysis of the qualitative data were generated for the purposes of the study and should be validated and further refined in future studies of treatment seeking behavior among older adults.

\section{Conclusions and Future Directions}

This exploratory study contributes to the literature on how older adults decide to initiate and remain in treatment for depression, and how this process is impacted by prior mental health treatment experience. Although the results are preliminary, they suggest that primary-care based interdisciplinary mental health programs work to equalize treatment initiation rates among older adults with and without a history of mental health treatment. Additional outreach and orientation may be needed to improve psychotherapy engagement among older adults who are initiating psychotherapy for the first time. Outreach efforts could include education about the goals and expectations of psychotherapy and addressing any individual-level barriers to treatment. 
References

Areán, P. A., Ayalon, L., Hunkeler, E., Lin, E. H. B., Tang, L., Harpole, L., et al. (2005). Improving depression care for older, minority patients in primary care. Medical Care, 43, 381-390.

Beekman, A. T. S., Penninx, B. W. J. H., Deeg, D. J. H., de Beurs, E., Geerlings, S. W., \& van Tilburg, W. (2002). The impact of depression on the well-being, disability and use of services in older adults: A longitudinal perspective. Acta Psychiatrica Scandinavica, 105, 20-27.

Berg, C. A., Meegan, S. P., \& Klaczynski, P. (1999). Age and experiential differences in strategy generation and information requests for solving everyday problems. International Journal of Behavioral Development, 23, 615-639.

Bohlmeijer, E., Prenger, R., Taal, E., \& Cuijpers, P. (2010). The effects of mindfulnessbased stress reduction therapy on mental health of adults with a chronic medical disease: A meta-analysis. Journal of Psychosomatic Research, 68, 539-544.

Crabb, R., \& Hunsley, J. (2006). Utilization of mental health care services among older adults with depression. Journal of Clinical Psychology, 62, 299-312.

Cronkite, R. C., \& Moos, R. H. (1995). Life context, coping processes, and depression. In E. E. Beckham \& W. R. Leber (Eds.), Handbook of Depression (pp. 569-587). New York, NY: Guilford Press.

Crystal, S., Sambamoorthi, U., Walkup, J. T., \& Akincigil, A. (2003). Diagnosis and treatment of depression in the elderly Medicare population: Predictors, disparities, and trends. Journal of the American Geriatrics Society, 51, 17181728. 
Epstein, S. (1990). Cognitive-experiential theory. In L. Previn (Ed.), Handbook of personality theory and research (pp. 165-192). New York: Guilford Press.

Epstein, S. (1991). Cognitive-experiential self-theory: An integrative theory of personality. In R. Curtis (Ed.), The self with others: Convergences in psychoanalytic, social, and personality psychology (pp. 111-137). New York: Guilford Press.

Epstein, S., Pacini, R., Denes-Raj, V., \& Heier, H. (1996). Individual differences in intuitive-experiential and analytical-rational thinking styles. Journal of Personality and Social Psychology, 71, 390-405.

Finucane, M. L. (2008). Emotion, affect, and risk communication with older adults: Challenges and opportunities. Journal of Risk Research, 11, 983-997.

Fiske, A., Wetherell, J. L., \& Gatz, M. (2009). Depression in older adults. Annual Review of Clinical Psychology, 5, 363-389.

Jeste, D. V., Alexopoulos, G. S., Bartels, S. J., Cummings, J. L., Gallo, J. J., Gottlieb, G. L., et al. (1999). Consensus statement on the upcoming crisis in geriatric mental health: Research agenda for the next 2 decades. Archives of General Psychiatry, $56,848-853$.

Klap, R., Unroe, K. T., \& Unützer, J. (2003). Caring for mental illness in the United States: A focus on older adults. American Journal of Geriatric Psychiatry, 11, 517-524.

Meeks, S. M., Murrell, S. A., \& Mehl, R. C. (2000). Longitudinal relationships between depressive symptoms and health in normal older and middle-aged adults. Psychology and Aging, 15, 100-109. 
Mikels, J. A., Löckenhoff, C. E., Maglio, S. J., Carstensen, L. L., Goldstein, M. K., \& Garber, A. (2010). Thinking with your heart or your head: Focusing on emotions versus information differentially influences the decisions of younger and older adults. Psychology and Aging, 16, 87-95.

Ogrodniczuk, J. S., Joyce, A. S., \& Piper, W. E. (2005). Strategies for reducing patientinitiated premature termination of psychotherapy. Harvard Review of Psychiatry, 13, 57-70.

Peters, E., Finucane, M. L., MacGregor, D. G., \& Slovic, P. (2000). The bearable lightness of aging: Judgment and decision processes in older adults. In P. C. Stern \& L. L. Carstensen (Eds.), The aging mind: Opportunities in cognitive research (pp. 144-165). Washington, DC: National Academies Press.

Peters, E., Hess, T. M., Västfjäll, D., \& Auman, C. (2007). Adult age differences in dual information processes: Implications for the role of affective and deliberative processes in older adults' decision making. Perspectives on Psychological Science, 2, 1-23.

Pierce, P. F. (1993). Deciding on breast cancer treatment: A description of decision behavior. Nursing Research, 42, 22-28.

Qualls, S. H. (1998). Training in geropsychology: Preparing to meet the demand. Professional Psychology: Research and Practice, 29, 23-28.

Sirey, J. A., Bruce, M. L., \& Kales, H. C. (2010). Improving antidepressant adherence and depression outcomes in primary care: the treatment initiation and participation (TIP) program. American Journal of Geriatric Psychiatry, 18, 554562. 
Sirey, J. A., Bruce, M. L., Alexopoulos, G. S., (2005). The treatment initiation program: An intervention to improve depression outcomes in older adults. American Journal of Psychiatry, 162, 184-186.

Spitzer, R. L., Kroenke, K., \& Williams, J. B. W. (1999). Validation and utility of a selfreport version of PRIME-MD: The PHQ primary care study. Journal of the American Medical Association, 282, 1737-44.

Wittink, M. N., Dahlberg, B., Biruk, C., \& Barg, F. K. (2008). How older adults combine medical and experiential notions of depression. Qualitative Health Research, 18, 1174-1183.

Woodhead, E. L., Ivan, I. I., \& Emery, E. E. (2012). An exploratory study of inducing positive expectancies for psychotherapy. Aging and Mental Health, 16, 162-166.

Woodhead, E. L., Lynch, E. B., Edelstein, B. A. (2011). Decisional strategy determines whether frame influences treatment preferences for medical decisions. Psychology and Aging, 26, 285-294.

Yesavage, J. A., Brink, T. L., Rose, T. L., Lum, O., Huang, V., Adey, M. B., et al. (1983). Development and validation of a geriatric depression screening scale: A preliminary report. Journal of Psychiatric Research, 17, 37-49.

Yang, J. A., \& Jackson, C. L. (1998). Overcoming obstacles in providing mental health treatment to older adults: Getting in the door. Psychotherapy: Theory, Research, and Practice, Training, 35, 498-505. 


\section{Acknowledgements}

Erin L. Woodhead, Ph.D. is now at the Department of Psychology at San José State University. The authors would like to thank the BRIGHTEN program Project Coordinators, Laurie Bederow, LCSW and Grisel Rodriguez-Morales, MSW, LSW, who assisted with participant recruitment. This work was supported by the Foundation for Informed Medical Decision Making [FIMDM 0145-1], and the Substance Abuse and Mental Health Services Administration (SAMHSA) Center for Mental Health Services [1H79SM058673-01]. 
Table 1

Participant Demographic Characteristics $(N=50)$

\begin{tabular}{|c|c|c|c|c|}
\hline Variable & $\mathrm{n}$ & $\%$ & $M$ & $S D$ \\
\hline Geriatric Depression Scale (GDS) & & & 7.04 & 3.54 \\
\hline \multicolumn{5}{|l|}{ History of Mental Health Treatment } \\
\hline Yes & 33 & 66.0 & & \\
\hline No & 17 & 34.0 & & \\
\hline \multicolumn{5}{|l|}{ Gender } \\
\hline Female & 41 & 82.0 & & \\
\hline Male & 9 & 18.0 & & \\
\hline \multicolumn{5}{|l|}{ Education } \\
\hline Less than $12^{\text {th }}$ grade & 7 & 14.0 & & \\
\hline HS/GED/Voc Tech Diploma & 10 & 20.0 & & \\
\hline Some College & 10 & 20.0 & & \\
\hline Bachelor's degree & 8 & 16.0 & & \\
\hline Graduate Work & 15 & 30.0 & & \\
\hline \multicolumn{5}{|l|}{ Race } \\
\hline White & 26 & 52.0 & & \\
\hline Non-white & 24 & 48.0 & & \\
\hline \multicolumn{5}{|l|}{ Self-Reported Health } \\
\hline Excellent/Very Good & 1 & 2.0 & & \\
\hline Very Good & 5 & 10.0 & & \\
\hline Good & 25 & 50.0 & & \\
\hline Fair & 12 & 24.0 & & \\
\hline Poor & 7 & 14.0 & & \\
\hline
\end{tabular}

Note. GDS score did not vary significantly by gender (men: $\mathrm{M}=8.0, \mathrm{SD}=2.9$; women: $6.8, \mathrm{SD}=3.7$ ) or race (white: $\mathrm{M}=7.1, \mathrm{SD}=3.5$; non-white: $7.0, \mathrm{SD}=3.9$ ). 
Table 2

Psychotherapy Engagement by Race, Treatment Modality, and Depression Severity

\begin{tabular}{lllllll}
\hline & \multicolumn{2}{l}{ Race } & \multicolumn{3}{l}{ Treatment Modality } & \multicolumn{2}{l}{ Depression Severity } \\
\cline { 2 - 7 } & White & Non-white & IPT & CBT & Negative Screen & Positive Screen \\
& $(\mathrm{n}=26)$ & $(\mathrm{n}=24)$ & $(\mathrm{n}=8)$ & $(\mathrm{n}=30)$ & $(\mathrm{n}=14)$ & $(\mathrm{n}=36)$ \\
\hline Started Treatment & $88.5 \%$ & $71.4 \%$ & $100.0 \%$ & $93.3 \%$ & $71.4 \%$ & $83.3 \%$ \\
Terminated Early & $15.4 \%$ & $14.3 \%$ & $0.0 \%$ & $16.7 \%$ & $7.1 \%$ & $19.4 \%$ \\
Number of Sessions & $9.8(8.8)$ & $7.5(6.4)$ & $5.4(6.9)$ & $11.0(8.1)$ & $7.3(6.0)$ & $9.6(8.7)$ \\
Attendance Rate & $83.1(23.1)$ & $68.0(39.2)$ & $74.6(35.5)$ & $85.5(17.1)$ & $80.1(31.9)$ & $75.7(31.3)$
\end{tabular}

Note. For number of sessions and attendance rate, values reported are means and standard deviations. GDS score was dichotomized as below 5 or greater than or equal to 5 . 
Table 3

Coding Categories for Motivation to Attend Psychotherapy

\begin{tabular}{|c|c|c|}
\hline Theme & Transcript Example & \% Endorsing \\
\hline Influence of Family Issues & $\begin{array}{l}\text { "I have some amends I would like to make to my children. I have five kids and only one is } \\
\text { speaking to me, so I was hoping to take care of that if I could." }\end{array}$ & $32.0 \%$ \\
\hline Health Motivations & $\begin{array}{l}\text { "I am coming because I am nervous about my surgery. I am really worried about my health and } \\
\text { that I am going to die." }\end{array}$ & $16.0 \%$ \\
\hline $\begin{array}{l}\text { Positive Outcomes Seen in } \\
\text { Others }\end{array}$ & $\begin{array}{l}\text { "To have to move was hard for him, but he did so well as a result of the counseling. She helped } \\
\text { him find and successfully move to a new apartment." }\end{array}$ & $40.0 \%$ \\
\hline $\begin{array}{l}\text { Beliefs About Treatment } \\
\text { Outcomes }\end{array}$ & $\begin{array}{l}\text { "I want the tools to both understand and you know, understand what's happening to me, } \\
\text { understand what's going on, and make really good decisions." }\end{array}$ & $22.0 \%$ \\
\hline $\begin{array}{l}\text { Experience of Depressive } \\
\text { Symptoms }\end{array}$ & $\begin{array}{l}\text { "I notice that I'm letting go of many things that I didn't let go before. For instance, I was always } \\
\text { ready to go out and do things. Those things never bothered me. And now, my habits are } \\
\text { changing. And I don't like them." }\end{array}$ & $54.0 \%$ \\
\hline
\end{tabular}

